\title{
Fenomenologia a eksperymenty empiryczne
}

\begin{abstract}
In recent years, in cognitive science (especially influenced by the concept of the embodied mind), have been emerging proposals to use phenomenology methods in the cognitive considerations, and overcome the so-called explanatory gap. Good examples of these proposals are neurophenomenology and front-loaded phenomenology, which have been briefly characterized. Next, I will describe the biofeedback (BF) HRV mechanism, which according to the hypothesis, may be an effective tool supporting the above attempts to implement phenomenology for neurobiological research. To sum up aim of this article is: presenting the first-person data problem in cognitive science; describeing the exemplary methods and role of phenomenology in empirical research, and proposeing BF HRV as an effective tool to achieve the psychophysiological state postulated by the above methods.
\end{abstract}

Keywords: neurophenomenology, biofeedback, subjectivity

Niniejszy tekst ma na celu syntetyczne zaprezentowanie zagadnienia relacji danych pierwszo- i trzecioosobowych na gruncie badań kognitywnych oraz problematyki, jaka się z tym wiąże. W pierwszej części przedstawię coraz popularniejszą tendencję do stosowania metodologii fenomenologicznej w obszarze neuronauk, mających wspólnie przezwyciężyć dychotomię pierwszo- i trzecioosobowe, a przez to przyczynić się do pełniejszego zrozumienia fenomenu umysłowości. Sięganie po narzędzia fenomenologiczne wiąże się z popularną w ostatnim czasie w kognitywistyce i filozofii umysłu koncepcją umysłu ucieleśnionego i osadzonego w środowisku [Varela, Thompson i Rosch, 1991]. W tym artykule skupię się na dwóch propozycjach włączenia metod fenomenologii do praktyki badawczej neuronauk: neurofenomenologii [Lutz i Thompson, 2003; Lutz, 2002] oraz fenomenologii fazy wstępnej zaproponowanej przez Gallaghera [2017]. Postaram się scharakteryzować krótko obie propozycje oraz rozważyć ich potencjalną użyteczność w próbie rozwiązania problematyki danych pierwszoosobowych. W ostatniej części omówię mechanizm BF HRV, który zgodnie ze stawianą w artykule hipotezą może stanowić efektywne narzędzie wspomagające dla przywołanych propozycji udziału fenomenologii w badaniach neuronaukowych. 
Rozwój nauk kognitywnych oraz precyzyjnych metod neuroobrazowania zachęcił w ostatnich latach do rozważenia możliwych metod rzetelnego opisu zjawisk pierwszoosobowych [Lutz i in., 2002; Lutz i Thompson, 2003]. Problem oczywiście nie jest nowy i dotyczy przepaści między danymi pierwszoosobowymi, mającymi charakter jakościowy, a danymi obiektywnymi, trzecioosobowymi, dostarczanymi przez naukę. Problematyka ta stanowi znaczny obszar badań w samej filozofii umysłu, dlatego nie będę jej tutaj rekonstruował, warto jedynie wspomnieć, że istniejące stanowiska obejmujące to zagadnienie to cały wachlarz rozwiązań, od tych negujących znaczenie stanów umysłowych [Churchland, 1988, 1996], traktujących je jako fikcje [Dennett, 2016], koncepcje pośrednie [Searle, 2015], po te przypisujące stanom umysłowym i doświadczeniom mentalnym zasadniczą rolę, traktując je jako zjawiska dające się badać w sposób systematyczny [Gallagher, 1997; Gallese, 2009; Gallagher i Zahavi, 2015]. Pojawiają się więc pytania o to, czy fenomenologia może efektywnie współpracować z kognitywistyką, a także czy może zostać znaturalizowana [Roy i in., 1999; Petit, 1999]. Chociaż niektórzy współcześni fenomenologowie są raczej sceptyczni wobec tego pomysłu [Zahavi, 2011, 2013].

Coraz większa część badaczy utrzymuje, że fenomenologia oraz nauki kognitywne mogą i powinny wypracować wspólną płaszczyznę porozumienia, badają bowiem te same zjawiska, takie jak percepcja czy pamięć [Gallagher i Zahavi, 2015], a wspólny dialog może być obustronnie korzystny [Gallagher, 1997; Ratcliffe, 2006; Noë, 2007]. W przytaczanej literaturze projekty naturalizacji fenomenologii podzielono najogólniej na słabe oraz silne [Gallagher i Varela, 2010], jednak najistotniejsza jest próba przystosowania metod fenomenologicznych w taki sposób, aby mogły wejść w efektywny i dwustronnie wzbogacający dialog z neuronaukami czy szerzej kognitywistyką [Gallagher, 1997]. Jak zauważają zwolennicy integracji obu metod: „(...) fenomenologia może posiadać centralne znaczenie dla nauk kognitywnych, a także może czerpać z badań empirycznych prowadzonych w ramach tych nauk" [Gallagher i Varela, 2010, s. 77]. Co więcej, opisy fenomenologiczne i dane trzecioosobowe mogą okazać się komplementarne [Gallagher i Zahavi, 2015]. Francisco Varela, jeden z ważniejszych teoretyków neurofenomenologii, stwierdza, że:

Fenomenologiczne ujęcia struktury doświadczenia oraz ich odpowiedniki z nauk kognitywnych są ze sobą związane za pomocą obustronnych uwarunkowań. (...) kładąc nacisk na wzajemne uwarunkowanie obu ujęć, można badać ich powiązania, towarzyszące im wyzwania i wglądy, a także sprzeczności. (...) Metodyczne ujęcia pierwszoosobowe powinny być integralnym składnikiem oceny propozycji neurobiologicznych, a nie tylko przypadkową czy heurystyczną informacją [Varela, 2010, s. 59].

Celem nie jest więc uparte łączenie fenomenologii z podejściami naturalistyczny$\mathrm{mi}$, a raczej pokazanie dwóch równorzędnych perspektyw, które uzupełniane w rozsądny sposób, mogą przyczynić się do lepszego zrozumienia fenomenu umysłowości [Gallagher, 1997]. 
W ostatnich latach pojawiło się kilka wartych uwagi propozycji naturalizacji fenomenologii (np. poprzez jej zmatematyzowanie [zob. np. Marbach, 1993; Roy i in., 1999]), jednak w tekście skupię się na dwóch, będących istotnymi z uwagi na możliwość wzbogacenia ich o proponowaną tutaj metodę BF HRV. Pierwszą z nich stanowi neurofenomenologia [Roy i in., 1999; Rudrauf i in., 2003], postulująca metodyczne katalogowanie danych przekazywanych przez badane osoby, które uprzednio należałoby odpowiednio do tego przygotować (podobne pomysły można znaleźć w heterofenomenologii proponowanej przez Dennetta [2003, 2016]). Natomiast drugim projektem, zbliżonym, ale różniącym się w kilku zasadniczych punktach, jest fenomenologia fazy wstępnej [Gallagher, 2017].

Przedstawiciele neurofenomenologii przekonują, że w badaniu świadomości fenomenalnej nie powinno się odrzucać perspektywy pierwszoosobowej [Varela, 2010]. Jeden $\mathrm{z}$ ważniejszych badaczy podejmujących ten problem określa mianem neurofenomenologii: „(...) poszukiwania zmierzające do połączenia współczesnej kognitywistyki z metodycznym ujęciem ludzkiego doświadczenia, nawiązującym do dziedzictwa kontynentalnej tradycji fenomenologicznej" [Varela, 2010, s. 1].

Aby jednak cały projekt był konsekwentny, postuluje się wprowadzenie nowych technik badawczych, na przykład opracowanie metodologii badań pierwszoosobowych, umożliwiającej sporządzenie dokładnego opisu doświadczenia, w sposób rzetelny i intersubiektywny [Gallagher i Zahavi, 2015]. Opis taki może być osiągnięty dzięki metodom proponowanym już przez Husserla [1975, 2000; Zahavi, 2012], polegającym na redukcji fenomenologicznej, wzięciu $w$ nawias nastawienia naturalnego i dążeniu do wglądu w świadomościowe niezmienniki [Varela, 2010; Gładziejewski, 2010]. Kolejnym etapem będzie właściwe zestawienie charakterystyki uzyskanej z perspektywy fenomenologii z wynikami badań neurobiologicznych, co ma umożliwić wskazanie korelacji zachodzących między doświadczeniem fenomenalnym a towarzyszącą mu aktywnością neuronalną [Gallagher, 1997].

Przywoływany już Varela widzi w tej metodzie rozwiązanie tzw. trudnego problemu świadomości [Varela, 2010] - chociaż trafniej byłoby powiedzieć: rozwiązanie luki eksplanacyjnej [Lutz i Thompson, 2017]. Rozwiązanie to ma polegać na próbie wykroczenia poza ramę pierwszo-trzecioosobowe:

(...) w konsekwencji zwykłe przeciwstawienie ujęć pierwszoosobowych ujęciom trzecioosobowym jest błędne. Każe nam ono zapomnieć, że - podobnie jak ujęcia pierwszoosobowe - tak zwane obiektywne ujęcia trzecioosobowe powstają w obrębie wspólnoty konkretnych osób, żyjących w określonym środowisku społecznym i naturalnym (...). Linia oddzielająca podejście rygorystyczne od podejścia pozbawionego rygoru nie przebiega pomiędzy ujęciem trzecio- i pierwszoosobowym. Natomiast wyróżnia ona opisy uzyskane na podstawie jasnych reguł metodologicznych, które gwarantują ich uprawomocnienie w obrębie społeczności, co czyni takie opisy częścią wiedzy powszechnie uznawanej [Varela, 2010, s. 52].

Autor wskazuje na użyteczność fenomenologii w kontekście badań z zakresu kognitywistyki, koncentrujących się na takich zjawiskach jak uwaga, emocje czy poczucie sprawstwa i upływu czasu [Varela, 2010]. Co więcej, zaznacza, że wraz z rozwojem 
technologii umożliwiającej dokładniejsze badanie mózgu niezbędni będą „badacze o wzrastającej kompetencji w zakresie opisów i dystynkcji fenomenologicznych" [Varela, 2010, s. 54].

Neurofenomenologia zakłada systematyczne podejście do danych pierwszoosobowych uzyskiwanych od badanych osób. Zwolennicy tego podejścia sugerują, aby zarówno osoby badane, jak i eksperymentatorzy zostali odpowiednio przeszkoleni w metodologii fenomenologicznej [Roy i in., 1999]. Metoda ta miałaby wspomóc badania eksperymentalne poprzez dostarczenie stałych sposobów gromadzenia i katalogowania danych pierwszoosobowych, umożliwiając tym samym ich bardziej obiektywne i uporządkowane analizowanie [Gallagher, 2017]. Jak wskazują autorzy, ten rodzaj pierwszoosobowych danych jest często ignorowany, mimo że mógłby znacząco je wzbogacić [Lutz i Thompson, 2017]. Praktyki tego typu są już podejmowane, a ich wyniki wydają się obiecujące [zob. np. Lutz, 2002; Lutz i in., 2002; Le Van Quyen i Petitmengin, 2002; Petitmengin, 2006].

Zasadniczym celem tak rozumianej neurofenomenologii jest uzyskanie źródłowych i rzetelnych danych pierwszoosobowych, zebranych dzięki odpowiedniemu zastosowaniu metod fenomenologicznych [Lutz i Thompson, 2017]. Czym dokładnie są metody pierwszoosobowe? Roboczej definicji dostarczają Lutz i Thompson: są one „(...) metodycznymi praktykami, które badani mogą używać w celu zwiększenia wrażliwości na własne doświadczenie z chwili na chwilę (...), składające się z systematycznego treningu uwagi i emocjonalnej samoregulacji” [Lutz i Thompson, 2017, s. 459]. W kontekście możliwego zastosowania BF HRV definicja ta jest bardzo istotna.

Oczywiście badacze rozwijający ten kierunek dociekań są świadomi trudności, jakim jest na przykład fakt, że sprawozdania pierwszoosobowe mogą być wysoce nieprecyzyjne oraz ulegać zniekształceniom [Lutz i Thompson, 2017]. Ujęcie neurofenomenologiczne zaproponowane między innymi przez Varelę $[1996,2010]$ jest nadal rozwijane i doskonalone [Roy i in., 1999; Gallagher, 2003, 2007; Lutz, 2002; Lutz i Thompson, 2017].

Fenomenologia fazy wstępnej (ang. front-loaded phenomenology) jest koncepcją przywoływanego już wcześniej Gallaghera [Gallagher i Zahavi, 2015; Gallagher, 2017]. Zgodnie z intencjami autora ma ona na celu zaadaptowanie do badań empirycznych fenomenologii (a konkretnie wyników jej analiz np. wypracowanych przez nią odpowiednich pojęć czy rozróżnień) jako dziedziny wspomagającej projektowanie i planowanie eksperymentów [Gallagher, 2017]. Zdaniem autora takie zastosowanie fenomenologii umożliwi empiryczne testowanie jej wyników, a także „dialektyczny ruch pomiędzy uprzednimi ujęciami uzyskanymi w fenomenologii i wstępnymi testami, które określą lub poszerzą te ujęcia dla celów konkretnego eksperymentu (...)" [Gallagher, 2017, s. 448]. Gallagher przytacza kilka przykładów efektywnego wdrożenia tej metodologii [zob. Gallagher, 2017]. Propozycja ta nie odrzuca podejścia neurofenomenologicznego, kładzie jednak nacisk nie na szkolenie badanych technik fenomenologii, a raczej na wykorzystanie intuicji fenomenologicznych do planowania eksperymentów [Gallagher i Zahavi, 2015]. Fenomenologia fazy wstępnej miałaby umożliwić testowanie opisu fenomenologicznego i próby jego potwierdzenia, jej twórcy przywołują eksperymenty dotyczące poczucia sprawstwa oraz własności (ang. 
sense of ownership) i argumentują, że postulowana przez nich metoda może odegrać w takich przypadkach zasadniczą rolę [Gallagher i Zahavi, 2015].

\section{III}

Metodą mogącą okazać się pomocną przy przygotowywaniu powyższych interdyscyplinarnych projektów badawczych jest biofeedback HRV (ang. Heart Rate Variability). Najogólniej biofeedbackiem określa się technikę umożliwiającą dostarczanie odpowiedzi zwrotnej dotyczącej stanu organizmu uczestnika sesji. Innymi słowy, osoba poddająca się treningowi BF zostaje podłączona do aparatury monitorującej dany parametr fizjologiczny (może nim być temperatura, puls, oddech, aktywność elektryczna mózgu, reakcja skórno-galwaniczna itp. [Kubik, 2016]), którego wartość zostaje mu przedstawiona $\mathrm{w}$ formie liczbowej lub graficznej, zazwyczaj na ekranie komputera. Otrzymywanie danych ukazujących bieżące zmiany w organizmie pozwala uczestnikowi dostrzec korelację między tymi zmianami a czynnikami, na które ma bezpośredni i świadomy wpływ (np. oddech). Po odpowiednio długim treningu uczestnik uczy się pośrednio wpływać na dany parametr, utrzymując jego wartość na pożądanym poziomie [Giggins i in., 2013].

Jak już wspominano, wyróżnia się kilka rodzajów biofeedbacku, na przykład EEG, GSR czy temperaturowy [Kubik, 2016]. Jednak w kontekście omawianej problematyki warto zwrócić uwagę na tzw. biofeedback HRV, polegający na dostarczaniu uczestnikowi sesji informacji na temat zmienności rytmu serca i stanowiący efektywną metodę wywoływania tzw. odpowiedzi relaksacyjnej (ang. relaxation response) [Benson i Klipper, 1975].

Aby dobrze zrozumieć mechanizm BF HRV, warto zacząć od krótkiej charakterystyki odpowiedzi relaksacyjnej (OR), czyli stanu fizjologicznego, jaki może być wywołany przy odpowiednim zastosowaniu techniki $\mathrm{BF}^{1}$. Termin ten został użyty po raz pierwszy w latach 70. przez kardiologa Herberta Bensona [Benson i Klipper, 1975]. Stan fizjologiczny określany tym terminem charakteryzuje się między innymi obniżeniem ciśnienia tętniczego krwi, szybkości oddechu [Wallace i Benson, 1972] oraz zwiększeniem synchronizacji półkul mózgowych [Jacobs, 2001]. Mówiąc krótko, wywoływanie OR stosuje się w celu obniżenia poziomu napięcia i stresu. Ale w jaki sposób zachodzi to zjawisko?

Częstość rytmu serca jest ściśle skorelowana z rytmem oddechowym, co pozwala regulować wydajności natlenowania krwi w płucach [Lehrer, Vaschillo i Vaschillo,

\footnotetext{
${ }^{1}$ Należy tutaj zaznaczyć, że omawianie BF HRV jako metody pozwalającej wywołać odpowiedź relaksacyjną stanowi tylko przykład jej zastosowania, ważny z perspektywy omawianego problemu. BF HRV jest metodą szerszą i nie została stworzona jedynie do wywoływania OR. Jej zastosowanie jest zależne od potrzeb, równie dobrze można ją wykorzystać do wywołania reakcji całkowicie przeciwnej. BF HRV jest jedynie systemem umożliwiającym śledzenie bieżących zmian w organizmie (a dokładnie: zmienności rytmu serca), cel, jaki przyświeca śledzeniu tego parametru, to zupełnie inna sprawa. Podobnie jest z OR - jest to stan możliwy do wywołania dzięki licznym metodom, od medytacji po ćwiczenia fizyczne. BF HRV nie jest jedyną drogą do wywołania OR.
} 
2000]. Świadome oddziaływanie na wzrost HRV za pomocą kontroli i modulacji oddechu (zazwyczaj z częstotliwością rezonansową, w przybliżeniu $0,1 \mathrm{~Hz}$ ) wywołuje obniżenie objawów napięcia emocjonalnego [Wallace i Benson, 1972; Vaschillo, Vaschillo i Lehrer, 2006]. Wzrost ciśnienia tętniczego krwi zwiększa z kolei aktywność części współczulnej autonomicznego układu nerwowego poprzez zwiększoną aktywność baroreceptorów. Skutkuje to spadkiem częstości akcji serca oraz obniżeniem ciśnienia tętniczego krwi [Vaschillo, Vaschillo i Lehrer, 2006].

OR może być wywołana za pomocą wielu metod, również mających swoje źródła $\mathrm{w}$ tradycji dalekowschodniej, takich jak tai-chi, medytacja mindfulness [van der Zwan i in., 2015] albo ćwiczenia fizyczne (np. joga). Mają one na celu pobudzenie przywspółczulnej części autonomicznego układu nerwowego [Wallace i Benson, 1972]. Współcześnie efektywnym sposobem wywoływania OR jest charakteryzowana technika biofeedbacku HRV, oparta na pomiarze zmienności rytmu serca [Wheat i Larkin, 2010]. BF HRV ma pozytywny wpływ na stan psychofizjologiczny, zwiększając zdolność regulacji emocjonalnej poprzez podniesienie poziomu świadomości własnego ciała. Pozytywne emocje poprawiają między innymi kreatywność i elastyczność poznawczą [Fredrickson, 2001], wywoływanie OR prowadzi więc do pozytywnej modyfikacji funkcji psychicznych [Fredrickson, 2001; Hansen i in., 2004; Luft, Takase i Derby, 2009]. W warunkach klinicznych, stosując BF HRV, odnotowano poprawę funkcjonowania emocjonalnego w takich zaburzeniach jak: depresja [Karavidas i in., 2007], fobie [Kawachi i in., 1995; Reiner, 2008] czy zespół stresu pourazowego [Lande i in., 2010; Tucker i in., 2012].

Podsumowując, trening BF HRV poprzez świadomą regulację oddechu umożliwia efektywne ustabilizowanie pracy serca, a co za tym idzie - napięcia emocjonalnego, a także poprawę koncentracji, zwiększenie kontroli reakcji fizjologicznych organizmu [Francis, Penglis i McDonald, 2016], stabilizację emocjonalną (a przez to poznawczą) oraz podniesienie poziomu świadomości własnego ciała. W efekcie uczestnik uzyskuje możliwość większej kontroli emocjonalnej, a także lepszą koncentrację w czasie śledzenia, interpretacji oraz przekazywania innym informacji na temat swoich doświadczeń. Innymi słowy, efektywnie przeprowadzony trening BF HRV pozwala niejako „zneutralizować” potencjalne czynniki zakłócające i uzyskać stan „stabilny” dla danej osoby. Co więcej, parametry określające zmienność rytmu serca stanowią wiarygodne i obiektywne źródło informacji o stanie psychofizjologicznym danej osoby [Francis, Penglis i McDonald, 2016]. Umożliwia to stosunkowo proste i bezpośrednie śledzenie zależności między wartościami parametrów fizjologicznych a pierwszoosobowymi odczuciami relacjonowanymi przez badanego. W związku z powyższym BF HRV można potraktować jako narzędzie mogące stanowić element przygotowawczy do badań integrujących podejścia neurobiologiczne oraz fenomenologiczne.

Aby dostrzec potencjalną użyteczność techniki BF HRV jako narzędzia pomocniczego przy projektowaniu eksperymentów, warto ponownie zwrócić uwagę na kluczowe cechy prezentowanych wcześniej metod fenomenologicznych. Po pierwsze, neurofenomenologia słusznie kładzie szczególny nacisk na emocje [Lutz i Thompson, 2017], które są istotnym czynnikiem wpływającym na postrzeganie rzeczywistości oraz interpretacje wewnętrznych stanów umysłowych [Damásio, 2000, 2011]. Po drugie, przytoczony wcześniej cytat, zawierający definicję metod pierwszoosobowych 
(metodyczne praktyki, stosowane w celu zwiększenia wrażliwości na własne doświadczenia, składające się z systematycznego treningu uwagi oraz samoregulacji emocjonalnej [Lutz i Thompson, 2017]), jest bardzo celnym opisem mechanizmu BF HRV. Jak wynika z przytoczonych wcześniej badań, to właśnie BF HRV stanowi jedną z najlepszych technik treningu uwagi i regulacji emocjonalnej. BF HRV, w odróżnieniu od technik medytacyjnych, którymi był inspirowany, jest sprawdzoną metodą samokontroli emocjonalnej, umożliwiającą ponadto obiektywne katalogowanie wyników sesji oraz regularne śledzenie postępu. Obiektywność techniki, możliwość bieżącego śledzenia zmian emocjonalnych i prostota obsługi systemu czynią go potencjalnie bardzo użytecznym dla badań integrujących metody pierwszo- i trzecioosobowe. $\mathrm{Z}$ przeglądu literatury wynika, że dotychczas nie sugerowano zastosowania BF HRV jako elementu wspomagającego eksperymenty integrujące fenomenologię i neuronauki. Omawiana technika mogłaby posłużyć jako rodzaj sesji przygotowawczej do eksperymentu właściwego, mającej na celu ustabilizowanie funkcji emocjonalnych i poznawczych, a przez to wyeliminowanie zakłóceń w czasie relacjonowania przez badanego subiektywnych odczuć. Zabieg ten pozwoliłby niejako „wyostrzyć” metody fenomenologiczne stosowane w czasie badań. Jak już wspomniano, trening BF HRV nie jest czymś całkowicie nowym, pozwala jednak na efektywniejszą kontrolę i śledzenie całego procesu. Teoretycy neurofenomenologii dostrzegli potencjalną użyteczność medytacji dla metod fenomenologii [Varela, Thompson i Rosch, 1991]. Gallagher stwierdza, że: „(...) osoby długotrwale praktykujące medytację świadomości byłyby zdolne do wyizolowania lub wzmocnienia różnorodnych doświadczeń bądź też strategii poznawczych czy kierunkowania uwagi. Służyłoby to umożliwieniu naukowego badania tych doświadczeń bądź strategii za pomocą np. obrazowania mózgu czy eksperymentów behawioralnych" [cyt. za: Nowakowski i in., 2011, s. 188]. Omawiani autorzy wskazują więc cechy medytacji, takie jak koncentracja uwagi itp., uzyskiwane dzięki wywołaniu OR, jako czynniki mogące wspomóc eksperymenty neurofenomenologiczne. Nie wspominają jednak o BF HRV jako metodzie dużo bardziej użytecznej z punktu widzenia badań trzecioosobowych niż tradycyjna medytacja. Należy ponownie podkreślić, że sugerowana tu metoda nie ma stanowić narzędzia fenomenologii, a jedynie narzędzie przygotowawcze do badań, gdzie metody fenomenologii są wykorzystywane. Podejście fenomenologiczne polega na zawieszeniu przedsądów wpływających na interpretacje doświadczenia. BF HRV ma jedynie na celu wywołanie OR, która zgodnie z przywoływanymi badaniami poprawia koncentrację, umożliwiając tym samym efektywniejsze przekazanie bogactwa doświadczeń. Technika BF HRV poprawiająca kontrolę emocjonalną ma znaczenie z pierwszoosobowego punktu widzenia. Podejścia naturalizujące fenomenologię mają natomiast na celu naukowe, trzecioosobowe zbliżenie się do poznania świadomości. BF HRV nie zamierza rozwiązywać problemów świadomości, nie stanowi też narzędzia poznawczego. Zgodnie ze stawianą tezą ma znacznie skromniejszy cel - przygotowanie emocjonalne i poznawcze osoby poddającej się badaniu łączącemu techniki fenomenologiczne i trzecioosobowe, umożliwiając efektywniejsze raportowanie własnych doświadczeń. 


\section{BIBLIOGRAFIA}

Benson, H. i Klipper, M.Z. (1975). The Relaxation Response. New York: HarperCollins.

Churchland, P.S. (1988). Neurophilosophy: Toward a Unified Science of the Mind/Brain. Cambridge: MIT Press.

Churchland, P.S. (1996). The Hornswoggle Problem. Journal of Consciousness Studies, 3: 402-408.

Damásio, A. (2000). Tajemnica świadomości: ciało i emocje współtworzq świadomość. Poznań: Rebis.

Damásio, A. (2011). Jak umysł zyskał jaźń: konstruowanie świadomego mózgu. Poznań: Rebis.

Dennett, D.C. (2003). Who's on first? Heterophenomenology explained. Journal of Consciousness Studies, 11: 19-30.

Dennett, D.C. (2016). Świadomość. Kraków: Copernicus Center Press.

Francis, H.M., Penglis, K.M. i McDonald, S. (2016). Manipulation of heart rate variability can modify response to anger-inducing stimuli. Social Neuroscience, 11(5): 545-552.

Fredrickson, B.L. (2001). The role of positive emotions in positive psychology: The broaden-and-build theory of positive emotions. American Psychologist, 56(3): 218-226.

Gallagher, S. (1997). Mutual enlightenment: Recent phenomenology in cognitive science. Journal of Consciousness Studies, 4.

Gallagher, S. (2003). Phenomenology and experimental design: Toward a phenomenologically enlightened experimental science. Journal of Consciousness Studies, 10: 85-99.

Gallagher, S. (2005). Neurophilosophy and neurophenomenology. Phenomenology, 5: 293-316.

Gallagher, S. (2009). Neurophenomenology. W: T. Bayne, A. Cleeremans, P. Wilken (eds.), Oxford Companion to Consciousness (s. 470-472). Oxford: Oxford University Press.

Gallagher, S. (2017). Fenomenologia i projektowanie eksperymentów. Ku fenomenologicznie oświeconym naukom eksperymentalnym. W: J. Migasiński, M. Pokropski (red.), Główne problemy współczesnej fenomenologii. Warszawa: Wydawnictwa Uniwersytetu Warszawskiego.

Gallagher, S. i Varela, F. (2010). Przerysować mapę i przestawić czas: fenomenologia i nauki kognitywne. Avant, 1.

Gallagher, S. i Zahavi, D. (2015). Fenomenologiczny umyst. Warszawa: Wydawnictwo Naukowe PWN.

Gallese, V. (2009). Ucieleśniona symulacja: od neuronów po doświadczenie fenomenologiczne. W: A. Klawiter (red.), Formy aktywności umysłu. Ujęcia kognitywistyczne, t II. Warszawa: Wydawnictwo Naukowe PWN.

Giggins, O.M., Persson, U.M. i Caulfield, B. (2013). Biofeedback in rehabilitation. Journal of NeuroEngineering and Rehabilitation, 10: 60.

Gładziejewski, P. (2010). Neurofenomenologia: zaproszenie do dyskusji. Avant, 1.

Hansen, A.L., Johnsen, B.H., Sollers, J.J., Stenvik, K. i Thayer, J.F. (2004). Heart rate variability and its relation to prefrontal cognitive function: the effects of training and detraining. European Journal of Applied Physiology, 93(3): 263-72.

Husserl, E. (1975). Idee czystej fenomenologii i fenomenologicznej filozofii. Warszawa: PWN.

Husserl, E. (2000). Badania logiczne. Warszawa: Wydawnictwo Naukowe PWN.

Jacobs, G.D. (2001). Clinical applications of the relaxation response and mind-body interventions. Journal of Alternative and Complementary Medicine, 7(Suppl 1): 93-101.

Karavidas, M.K., Lehrer, P.M., Vaschillo, E., Vaschillo, B., Marin, H., Buyske, S., Malinovsky, I., Radvanski, D. i Hassett, A. (2007). Preliminary results of an open label study of heart rate variability biofeedback for the treatment of major depression. Applied Psychophysiology and Biofeedback, 32(1): 19-30.

Kawachi, I., Sparrow, D., Vokonas, P.S. i Weiss, S.T. (1995). Decreased heart rate variability in men with phobic anxiety (data from the Normative Aging Study). The American Journal of Cardiology, 75(14): 882-885. 
Kubik, P. (2016). Rodzaje biofeedbacku. Przegląd Lekarski, 73(3): 191-193.

Lande, R.G., Williams, L.B., Francis, J.L., Gragnani, C. i Morin, M.L. (2010). Efficacy of biofeedback for post-traumatic stress disorder. Complementary Therapies in Medicine, 18(6): 256-259.

Le Van Quyen, M. i Petitmengin, C. (2002). Neuronal dynamics and conscious experience: An example of reciprocal causation before epileptic seizures. Phenomenology and the Cognitive Sciences, 1: 169-180.

Lehrer, P., Vaschillo, E. i Vaschillo, B. (2000). Resonant frequency biofeedback training to increase cardiac variability: Rationale and manual for training. Applied Psychophysiology Biofeedback, 25: 177-191.

Luft, C.D.B., Takase, E. i Darby, D. (2009). Heart rate variability and cognitive function: effects of physical effort. Biological Psychology, 82(2): 164-168.

Lutz, A. (2002). Toward a neurophenomenology as an account of generative passages: A first empirical case study. Phenomenology and the Cognitive Sciences, 1 .

Lutz, A., Lachaux, J.-P., Martinerie, J. i Varela, F.J. (2002). Guiding the study of brain dynamics by using first-person data: Synchrony patterns correlate with ongoing conscious states during a simple visual task. Proceedings of the National Academy of Sciences of the United States of America, 99: 1586-1591.

Lutz, A. i Thompson, E. (2003). Neurophenomenology - integrating subjective experience and brain dynamics in the neuroscience of consciousness. Journal of Consciousness Studies, 10: $31-52$.

Lutz, A. i Thompson, E. (2017). Neurofenomenologia: integrowanie doświadczenia subiektywnego i dynamiki neuronalnej w neuronauce świadomości. W: J. Migasiński, M. Pokropski (red.), Główne problemy współczesnej fenomenologii. Warszawa: Wydawnictwa Uniwersytetu Warszawskiego.

Marbach, E. (1993). Mental Representation and Consciousness: Toward a Phenomenological Theory of Representation and Reference. Kluwer Academic Publishers.

Noë, A. (2007). The critique of pure phenomenology. Phenomenology and the Cognitive Sciences, 6: 231-245.

Nowakowski, P., Podgórski, J.S., Pokropski, M. i Wachowski, W. (2011). Od Vareli do innej fenomenologii. Wywiad z Shaunem Gallagherem, część I. Avant, 2.

Paul, M. i Garg, K. (2012). The effect of heart rate variability biofeedback on performance psychology of basketball players. Applied Psychophysiology and Biofeedback, 37(2): 131-44.

Petit, J.L. (1999). Constitution by movement: Husserl in light of recent neurobiological findings. W: J. Petitot, F.J. Varela, B. Pachoud, J.-M. Roy (eds.), Naturalizing Phenomenology. Stanford: Stanford University Press.

Petitmengin, C. (2006). Describing one's subjective experience in the second person: An interview method for the science of consciousness. Phenomenology and the Cognitive Sciences, 5.

Ratcliffe, M. (2006). Phenomenology, neuroscience, and intersubjectivity. W: H.L. Dreyfus, M.A. Wrathall (eds.), A Companion to Phenomenology and Existentialism (s. 329-345). Oxford: Blackwell Publishing.

Reiner, R. (2008). Integrating a portable biofeedback device into clinical practice for patients with anxiety disorders: results of a pilot study. Applied Psychophysiology Biofeedback, 33(1): 55-61.

Roy, J.-M., Petitot, J., Pachoud, B. i Varela, F.J. (1999). Beyond the gap: An introduction to naturalizing phenomenology. W: J. Petitot, F.J. Varela, B. Pachoud, J.-M. Roy (eds.), Naturalizing Phenomenology. Stanford: Stanford University Press.

Rudrauf, D., Lutz, A., Cosmelli, D., Lachaux, J.P. i Le Van Quyen, M. (2003). From autopoiesis to neurophenomenology: Francisco Varela's exploration of the biophysics of being. Biological Research, 36: 27-65.

Searle, J.R. (2015). Naturalizm biologiczny. Filo-Sofija, 28: 299-311. 
Tucker, P., Pfefferbaum, B., Jeon-Slaughter, H., Khan, Q. i Garton, T. (2012). Emotional stress and heart rate variability measures associated with cardiovascular risk in relocated Katrina survivors. Psychosomatic Medicine, 74(2): 160-168.

Varela, F. (1996). Phenomenology in Consciousness Research. Journal of Consciousness Studies, 3: 330-349.

Varela, F. (2010). Neurofenomenologia: metodologiczne lekarstwo na trudny problem. Avant, 1: $31-75$.

Varela, F., Thompson, E. i Rosch, E. (1991). The Embodied Mind: Cognitive Science and Human Experience. Cambridge: MIT Press.

Vaschillo, E.G., Vaschillo, B. i Lehrer, P.M, (2006). Characteristics of resonance in heart rate variability stimulated by biofeedback. Applied Psychophysiology and Biofeedback, 31(2): 129-142.

Wallace, R.K. i Benson, H. (1972). The physiology of meditation. Scientific American, 226(2): 84-90.

Wheat, A.L. i Larkin, K.T. (2010). Biofeedback of heart rate variability and related physiology: a critical review. Applied Psychophysiology and Biofeedback, 35(3): 229-242.

Zahavi, D. (2011). Fenomenologia a projekt naturalizacji. Avant, 2: 41-57.

Zahavi, D. (2012). Fenomenologia Husserla. Kraków: WAM.

Zahavi, D. (2013). Naturalized phenomenology: a desideratum or a category mistake? Royal Institute of Philosophy Supplement, 72: 23-42.

Zwan van der, J.E., de Vente, W., Huizink, A.C., Bögels, S.M. i de Bruin, E.I. (2015). Physical activity, mindfulness meditation, or heart rate variability biofeedback for stress reduction: a randomized controlled trial. Applied Psychophysiology and Biofeedback, 40: 257. 